УДК 634.1:631.54:338.43

06.01.01 Общее земледелие, растениеводство

ОБОСНОВАНИЕ ОПТИМАЛЬНЫХ

ПАРАМЕТРОВ РЕСУРСОЕМКОСТИ

ПРОИЗВОДСТВЕННО-ТЕХНОЛОГИЧЕСКИХ

ПРОЦЕССОВ В ПРОМЫШЛЕННОМ

ПЛОДОВОДСТВЕ И ПРЕДЕЛОВ

УСТОЙЧИВОСТИ АГРОЦЕНОЗОВ ПРИ

ТЕХНОГЕННЫХ ВОЗДЕЙСТВИЯХ*

Шадрина Жанна Александровна

д-р экон. наук, доцент,

зав. лабораторией экономики

РИНЦ SPIN-код: 6370-7329

Scopus Author ID: 57200413990

Федеральное государственное бюджетное

научное учреждение «Северо-Кавказский

федеральный научный иентр садоводства,

виноградарства, виноделия»,

Краснодар Россия

Шичиях Рустем Адамович

канд. экон. наук,

доцент кафедры менеджмента

SPIN-code: 3243-1971

Scopus Author ID: 5709405190

Федеральное государственное бюджетное

образовательное учреждение высшего образования

«Кубанский государственный аграрный

университет им. И.Т. Трубилина», Краснодар,

Россия

Данная статья посвящена вопросам определения критериев функционирования агроценозов.

Определено, что функционирование агроценозов во многом зависит от ресурсного потенциала: используемых экологических зон, применяемых технологий, технологических операций и регламентов. Основу эффективного воспроизводства и устойчивости агроценозов составляет оптимальный баланс используемых ресурсов. Цель работы заключается в обосновании оптимальных параметров ресурсоёмкости технологических процессов в плодоводстве и определении пределов устойчивости агроценозов при техногенных воздействиях. Дана интегральная оценка ресурсоёмкости производственнотехнологических процессов в промышленном плодоводстве в целях оптимизации ее параметров ресурсоемкости. Оптимум воспроизводственных возможностей и пределов устойчивости компонентов агроэкосистемы в сопоставимости с уровнем техногенной нагрузки достигается посредством нормирования допустимых антропогенных нагрузок в отдельных элементах
UDC 634.1:631.54:338.43

General agriculture and crop production

\section{SUBSTANTIATION OF OPTIMAL PARAMETERS OF RESOURCE INTENSITY OF PRODUCTION AND TECHNOLOGICAL PROCESSES IN INDUSTRIAL FRUIT GROWING AND SUSTAINABILITY LIMITS OF AGROCENOSISES UNDER ANTHROPOGENIC INFLUENCES*}

Shadrina Zhanna Aleksandrovna

Doctor of Economics, docent,

Head of the Laboratory of Economics

RSCI SPIN-code: 6370-7329

Scopus Author ID: 57200413990

Federal State Budget Scientific Institution

North Caucasian Federal Scientific Center

of Horticulture, Viticulture, Wine-making,

Krasnodar, Russia

Shichiyakh Rustem Adamovich

Candidate of Economics science

Associate Professor of Management

RSCI SPIN-code: 3243-1971

Scopus Author ID: 57094051900

Federal State Budgetary Educational Institution of

Higher Education "Kuban State Agrarian University named after I.T. Trubilin", Krasnodar, Russia

This article is devoted to the definition of criteria for the functioning of agrocenoses. It is determined that the functioning of agrocenoses largely depends on the resource potential: used ecological zones, applied technologies, technological operations and regulations. The basis of effective reproduction and sustainability of agrocenoses is the optimal balance of resources used. The work purpose is the substantiation of optimal parameters of resource intensity of the technological processes in horticulture and the determination of the limits of sustainability of agrocenoses under anthropogenic influences. The integrated assessment of resource intensity of production and technological processes in industrial fruit growing for optimization of its parameters of resource intensity is given. The optimum of reproduction possibilities and limits of stability of agroecosystem components in comparability with the level of technogenic load is achieved by means of regulation of permissible anthropogenic loads in separate elements of agroecosystem and resource balance of elements and processes. The limits of sustainability of fruit agrocenosis under

\footnotetext{
* Работа выполнена при поддержке РФФИ и администрации Краснодарского края № 18-410-230009 р._а и в рамках выполнения государственного задания
} 
агроэкосистемы и ресурсной сбалансированности организации элементов и процессов. Обоснованы пределы устойчивости плодовых агроценозов при техногенных воздействиях. Установлены регрессионные зависимости по технологическим процессам в разрезе отдельных видов используемых ресурсов: капитальные (амортизациоемкость), оборотные (материалоемкость и коэффициент закрепления) и трудовые (зарплатоемкость). Определен комплексный коэффициент эффективности экономического механизма ресурсосбережения. Обоснованы оптимальные параметры ресурсоемкости производственнотехнологических процессов в промышленном плодоводстве. Рассчитано нормативное значение совокупного индекса ресурсоемкости по технологическим процессам

Ключевые слова: РЕСУРСОЕМКОСТЬ, АГРОЦЕНОЗ, ПРОМЫШЛЕННОЕ ПЛОДОВОДСТВО, ТЕХНОГЕННЫЕ ВОЗДЕЙСТВИЯ, ПРЕДЕЛЫ, ПАРАМЕТРЫ anthropogenic influences are substantiated as well. Regression dependences on technological processes in the context of certain types of resources used are established: capital (depreciation), turnover (material consumption and coefficient of consolidation) and labor (wage). The complex coefficient of efficiency of the economic mechanism of resource saving is defined. The article substantiates optimal parameters of resource-intensive production and technological processes in industrial horticulture. We have also calculated the normative value of the total index of resource intensity of technological processes

DOI: http://dx.doi.org/10.21515/1990-4665-151-021

Введение. Устойчивость функционирования агроценозов и эффективность возделывания многолетних насаждений во многом зависит от ресурсного потенциала: используемых экологических зон, применяемых технологий, технологических операций и регламентов, энергетических, трудовых и материальных затрат. Основу эффективного воспроизводства и устойчивости агроценозов составляет оптимальный баланс используемых ресурсов. Основу устойчивости агроценозов (сохранение структуры и функций под воздействием внешней и внутренней среды) составляют оптимально-выстроенный баланс ресурсов, ориентированных на развитие воспроизводственных процессов. Воздействие факторов внешней и внутренней среды на устойчивое и сбалансированное развитие агроэкологической системы необходимо рассматривать в системной взаимосвязи всех составляющих еe элементов и компонентов (динамический оптимум) [1].

Целью данной работы являлось обоснование оптимальных параметров ресурсоёмкости производственно-технологических процессов 
в промышленном плодоводстве и определение пределов устойчивости агроценозов при техногенных воздействиях.

Методика исследования включает применение экономикостатистических методов, а так же методов системного и факторного анализа.

Результаты и обсуждение. Материально-вещественные изменения в системах с популяционным типом управления: порог минимума $-10^{-6}-10^{-8}$ раз от нормы; порог выхода из стационарного состояния (устойчивых колебаний без угрозы деструкции) - в среднем $10 \%$ от нормы (правило 10 $\%$; порог постепенной деструкции находится в среднем свыше $10 \%$ от нормы и до $10 \%$ величины от среднего прироста популяции (потенциала самовозобновления, саморегуляции); порог катастрофического саморасширения или самосужения под влиянием внешних факторов равен $10^{5}-10^{6}$, очень редко $-10^{7}-10^{8}$ раз по сравнению со средним числом особей в популяции. По остальным структурным компонентам агроэкосистемы пределы устойчивости составляют 0,38-0,62 от нормативных значений оценочных показателей.

Оптимум воспроизводственных возможностей и пределов устойчивости компонентов агроэкосистемы «определяется в аналитических границах функциональных зависимостей биологического интервала выживаемости и гипотетической взаимосбалансированностью прибыльности и экологичности производства» $[2,4]$.

Достижение оптимума воспроизводственных возможностей и пределов устойчивости компонентов агроэкосистемы в сопоставимости с уровнем техногенной нагрузки достигается посредством нормирования допустимых антропогенных нагрузок в отдельных структурных элементах агроэкосистемы и ресурсной сбалансированности организации элементов и процессов [3]. 
В целях оптимизации параметров ресурсоёмкости необходимо дать интегральную оценку ресурсоёмкости производственно-технологических процессов в промышленном плодоводстве (таблица 1). Для определения значения интегрального показателя ресурсоёмкости производственнотехнологических процессов в промышленном плодоводстве, нами используются следующие показатели:

- уровень рентабельности производства;

- ресурсоемкость технологических процессов, выраженная в показателях:

a) подготовка почвы;

б) разбивка участка, устройство опорно-шпалерной конструкции;
в) закладка насаждений;
г) уход за молодыми насаждениями;
д) уборка урожая.

Таблица 1 - Оценка ресурсоемкости производственно-технологических процессов

в промышленном плодоводстве

\begin{tabular}{|c|c|c|c|c|c|c|c|c|}
\hline \multirow[b]{3}{*}{ Год } & \multirow[b]{3}{*}{$\begin{array}{c}\text { Рентабель } \\
\text { ность } \\
\text { производс } \\
\text { тва, \% } \\
\text { (у) }\end{array}$} & \multicolumn{6}{|c|}{ Интегральная оценка ресурсоёмкости } & \multirow[b]{3}{*}{$\begin{array}{c}\text { Интеграл } \\
\text { ьный } \\
\text { показател } \\
\text { ь }\end{array}$} \\
\hline & & \multicolumn{6}{|c|}{ Технологические процессы } & \\
\hline & & $\begin{array}{c}\text { подгото } \\
\text { вка } \\
\text { почвы } \\
\left(\mathrm{x}_{1}\right)\end{array}$ & $\begin{array}{c}\text { разбивка } \\
\text { участка, } \\
\text { устройство } \\
\text { опорно- } \\
\text { шпалерной } \\
\text { конструкц } \\
\text { ии } \\
\left(\mathrm{x}_{2}\right)\end{array}$ & $\begin{array}{c}\text { закладк } \\
\text { a } \\
\text { насажд } \\
\text { ений } \\
\left(\mathrm{x}_{3}\right)\end{array}$ & $\begin{array}{c}\text { уход за } \\
\text { молоды } \\
\text { ми } \\
\text { насажде } \\
\text { ниями } \\
\left(\mathrm{x}_{4}\right)\end{array}$ & $\begin{array}{c}\text { уход за } \\
\text { плодонося } \\
\text { щими } \\
\text { насажден } \\
\text { иями } \\
\left(\mathrm{x}_{5}\right)\end{array}$ & $\begin{array}{c}\text { уборка } \\
\text { урожая } \\
\left(\mathrm{x}_{6}\right)\end{array}$ & \\
\hline 2010 & 52,4 & 0,654 & 2,912 & 2,121 & 0,239 & 0,966 & 0,092 & 0,664 \\
\hline 2011 & 50,3 & 0,674 & 2,916 & 2,129 & 0,242 & 0,961 & 0,095 & 0,672 \\
\hline 2012 & 52,9 & 0,658 & 2,898 & 2,124 & 0,235 & 0,96 & 0,093 & 0,663 \\
\hline 2013 & 50,9 & 0,642 & 2,894 & 2,126 & 0,237 & 0,964 & 0,096 & 0,665 \\
\hline 2014 & 49,5 & 0,669 & 2,915 & 2,132 & 0,24 & 0,971 & 0,097 & 0,674 \\
\hline 2015 & 53,6 & 0,678 & 2,913 & 2,125 & 0,241 & 0,968 & 0,098 & 0,677 \\
\hline 2016 & 50,2 & 0,668 & 2,899 & 2,126 & 0,246 & 0,969 & 0,09 & 0,667 \\
\hline 2017 & 43,8 & 0,673 & 2,9 & 2,128 & 2,244 & 0,662 & 0,091 & 0,908 \\
\hline 2018 & 57,5 & 0,663 & 2,911 & 2,127 & 0,242 & 0,965 & 0,094 & 0,670 \\
\hline
\end{tabular}


Анализируя данные таблицы 1 , следует отметить значительное влияние факторов ресурсоёмкости технологических процессов на рентабельность производства. Снижение рентабельности производства вызвано в значительной степени снижением показателя по уходу за плодоносящими насаждениями.

Уравнение регрессии, полученное в результате проведенного анализа, показывающее степень влияния на рентабельность производства частных показателей ресурсоемкости, выглядит следующим образом:

$$
y=664,9+6,8 \cdot x_{1}+70,9 \cdot x_{2}-346,6 \cdot x_{3}-18,0 \cdot x_{4}-96,3 \cdot x_{5} .
$$

Смысл данной методики состоит в следующем, чем ближе значение показателя, полученного в результате оценки степени соответствия «фактического распределения темпов роста частных показателей ресурсоемкости их распределению с учетом полезности затрат производственных ресурсов, к единице, тем выше эффективность развития экономического механизма ресурсосбережения с учетом предельной полезности затрат производственных ресурсов» [1].

Для оценки используются коэффициенты Спирмена и Кендалла:

$$
K_{s p}=1-\frac{6 \sum_{i=1}^{m} D_{i}^{2}}{m\left(m^{2}-1\right)},
$$

где $K_{s p}$ - коэффициент Спирмена;

$m$ - общее количество показателей;

$D_{i}-$ разность между рангами. 


$$
K_{\text {Ken }}=1-\frac{4 \sum_{i=1}^{m} S_{i}}{m(m-1)},
$$

где $K_{\text {Ken }}$ - коэффициент Кендалла;

$S_{i}-$ инверсия $i$-го показателя.

В результате проведенных расчетов коэффициент Спирмена составил 0,671, коэффициент Кэндалла 0,567. Комплексный коэффициент эффективности экономического механизма ресурсосбережения рассчитывается при помощи формулы:

$$
K_{э \phi}=\frac{\left(1+K_{s p}\right) \cdot\left(1+K_{K e n}\right)}{4} .
$$

Комплексный коэффициент эффективности составит 0,655. При оценке эффективности экономического механизма ресурсосбережения используется следующая шкала данного показателя (таблица 2).

Полученные значения комплексного коэффициента оценки свидетельствуют о том, что эффективность экономического механизма ресурсосбережения в промышленном плодоводстве находится на среднем уровне, то есть, как отмечали в ранних исследованиях «возникает необходимость в оптимизации показателей ресурсоемкости производственно-технологических процессов» [5].

Далее в таблице 2 представлена Шкала оценки эффективности экономического механизма ресурсосбережения в промышленном плодоводстве, распределенная на 3 интервала. 
Таблица 2 - Шкала оценки эффективности экономического механизма ресурсосбережения

\begin{tabular}{|c|l|}
\hline $\begin{array}{c}\text { Значения } \\
\text { ресурсоемкости }\end{array}$ & \multicolumn{1}{|c|}{ Семантическая интерпретация } \\
\hline $0,000 \leq K_{\text {э }} \leq 0,330$ & $\begin{array}{l}\text { Низкая эффективность развития экономического механизма } \\
\text { ресурсосбережения, то есть развитие экономического механизма } \\
\text { ресурсосбережения осуществлется без учета полезности } \\
\text { производственных ресурсов отраслевого производства }\end{array}$ \\
\hline $0,331 \leq K_{\text {эф }} \leq 0,660$ & $\begin{array}{l}\text { Средняя эффективность развития экономического механизма } \\
\text { ресурсосбережения, то есть при развитии экономического } \\
\text { механизма ресурсосбережения недостаточно учитывается } \\
\text { полезность производственных ресурсов отраслевого производста }\end{array}$ \\
\hline $0,661 \leq K_{э \phi} \leq 1,000$ & $\begin{array}{l}\text { Высокая эффективность развития экономического механизма } \\
\text { ресурсосбережения, то есть развитие экономического механизма } \\
\text { ресурсосбережения осуществляется на основе полезности } \\
\text { производственных ресурсов отраслевого производства }\end{array}$ \\
\hline Для определения оптимальных показателей ресурсоемкости
\end{tabular}

необходимо установить регрессионные зависимости по технологическим процессам в разрезе отдельных видов используемых ресурсов: капитальные (амортизациоемкость), оборотные (материалоемкость и коэффициент закрепления) и трудовые (зарплатоемкость) (таблица 3).

Далее для расчётного обоснования оптимальных показателей ресурсоемкости необходимо продифференцировать полученные уравнения регрессии (таблица 4). 
Таблица 3 - Регрессионные зависимости показателей ресурсоёмкости по технологическим процессам

\begin{tabular}{|c|c|c|c|c|}
\hline \multirow{2}{*}{$\begin{array}{c}\text { Технологический } \\
\text { процесс }\end{array}$} & \multicolumn{4}{|c|}{ Показатели ресурсоемкости } \\
\hline & амортизациоемкость & материалоемкость & коэффициент закрепления & зарплатоемкость \\
\hline $\begin{array}{l}\text { Предпосадочная } \\
\text { подготовка почвы }\end{array}$ & $\mathrm{Am}=-0,016 \mathrm{x}^{2}+0,034 \mathrm{x}+0,125 \epsilon$ & $M e=-0,983 x^{2}+1,726 x+1,584$ & $\mathrm{~K}_{3}=0,184 \cdot \mathrm{x}^{2}-0,9947 \cdot \mathrm{x}+3,329$ & $3 e=0,062 \cdot x^{2}-0,0055 \cdot x-0,0125$ \\
\hline $\begin{array}{lr}\text { Разбивка } & \text { участка, } \\
\text { устройство } & \text { опорно- } \\
\text { шпалерной } & \\
\text { конструкции } & \text { и } \\
\text { мелиоративной } \\
\text { системы }\end{array}$ & $A M=-0,012 x^{2}+0,0013 x+0,067$ & $M e=-1,28 \cdot x^{2}+13,95 \cdot x-7,222$ & $K_{3}=0,161 \cdot x^{2}-2,756 \cdot x+11,155$ & $3 e=0,121 \cdot x^{2}-0,032 \cdot x+0,043$ \\
\hline Закладка насаждений & $\mathrm{Am}_{\mathrm{M}}=-0,19 \cdot \mathrm{x}^{2}+0,075 \cdot \mathrm{x}+0,312$ & $\mathrm{Me}=0,14 \cdot \mathrm{x}^{2}-1,108 \cdot \mathrm{x}+4,926$ & $\mathrm{~K}_{3}=0,52 \cdot \mathrm{x}^{2}-4,772 \cdot \mathrm{x}+8,84$ & $3 e=0,324 \cdot x^{2}-0,27 \cdot x+0,362$ \\
\hline $\begin{array}{l}\text { Уход за молодыми } \\
\text { неплодоносящими } \\
\text { насаждениями }\end{array}$ & $\mathrm{Am}=-0,09 \cdot \mathrm{x}^{2}+0,019 \cdot \mathrm{x}+0,178$ & $\mathrm{Me}=0,862 \cdot \mathrm{x}^{2}-0,99 \cdot \mathrm{x}+0,452$ & $K_{3}=0,283 \cdot x^{2}-0,385 \cdot x+0,785$ & $3 e=0,271 \cdot x^{2}-0,218 \cdot x+0,35$ \\
\hline $\begin{array}{l}\text { Уход за вступающими } \\
\text { и } \\
\text { насаждениями } \\
\end{array}$ & $A M=-0,181 \cdot x^{2}+0,399 x+0,885$ & $\mathrm{Me}=0,612 \cdot \mathrm{x}^{2}-3,233 \cdot \mathrm{x}+5,262$ & $K_{3}=0,151 \cdot x^{2}-0,948 \cdot x+3,936$ & $3 e=1,24 \cdot x^{2}-1,664 \cdot x+1,095$ \\
\hline Уборка урожая & $\mathrm{Am}=-0,014 \mathrm{x}^{2}+0,0012 \mathrm{x}+0,054$ & $\mathrm{Me}=0,124 \cdot \mathrm{x}^{2}-0,0087 \cdot \mathrm{x}-0,08$ & $\mathrm{~K}_{3}=0,924 \cdot \mathrm{x}^{2}-0,078 \cdot \mathrm{x}-0,8$ & $3 e=0,887 \cdot x^{2}-1,038 \cdot x+0,736$ \\
\hline
\end{tabular}


Таблица 4 - Расчётное обоснование оптимальных показателей ресурсоемкости по технологическим процессам в промышленном плодоводстве

\begin{tabular}{|c|c|c|c|c|}
\hline \multirow[b]{2}{*}{ Технологический процесс } & \multicolumn{4}{|c|}{ Показатели ресурсоемкости } \\
\hline & амортизациоемкость & материалоемкость & $\begin{array}{c}\text { коэффициент } \\
\text { закрепления } \\
\end{array}$ & зарплатоемкость \\
\hline \multicolumn{5}{|c|}{ Предпосадочная подготовка почвы } \\
\hline $\begin{array}{l}\text { - дифференцированное } \\
\text { уравнение регрессии }\end{array}$ & $\mathrm{D}_{\mathrm{AM}}=-0,032 \cdot \mathrm{x}+0,034$ & $\mathrm{D}_{\mathrm{Me}}=-1,966 \cdot \mathrm{x}+1,726$ & $\mathrm{D}_{\mathrm{K} 3}=0,368 \cdot \mathrm{x}-0,9947$ & $D_{3 e}=0,124 \cdot x^{2}-0,0055$ \\
\hline - оптимальное значение & 0,106 & 0,878 & 2,703 & 0,044 \\
\hline \multicolumn{5}{|c|}{ Разбивка участка, устройство опорно-шпалерной конструкции и мелиоративной системы } \\
\hline $\begin{array}{l}\text { - дифференцированное } \\
\text { уравнение регрессии }\end{array}$ & $\mathrm{D}_{\mathrm{AM}}=-0,024 \cdot \mathrm{x}+0,0013$ & $D_{\mathrm{Me}}=-2,56 \cdot \mathrm{x}+13,95$ & $\mathrm{D}_{\mathrm{K} 3}=0,322 \cdot \mathrm{x}-2,756$ & $D_{3 e}=0,242 \cdot x-0,032$ \\
\hline - оптимальное значение & 0,054 & 5,448 & 8,560 & 0,132 \\
\hline \multicolumn{5}{|c|}{ Закладка насаждений } \\
\hline $\begin{array}{l}\text { - дифференцированное } \\
\text { уравнение регрессии }\end{array}$ & $\mathrm{D}_{\mathrm{AM}}=-0,38 \cdot \mathrm{x}+0,075$ & $\mathrm{D}_{\mathrm{Me}}=0,28 \cdot \mathrm{x}-1,108$ & $\mathrm{D}_{\mathrm{K}}=1,04 \cdot \mathrm{x}-4,772$ & $D_{3 e}=0,648 \cdot x^{2}-0,27$ \\
\hline - оптимальное значение & 0,197 & 3,958 & 4,588 & 0,416 \\
\hline \multicolumn{5}{|c|}{ Уход за молодыми неплодоносящими насаждениями } \\
\hline $\begin{array}{l}\text { - дифференцированное } \\
\text { уравнение регрессии }\end{array}$ & $\mathrm{D}_{\mathrm{AM}}=-0,18 \cdot \mathrm{x}^{2}+0,019$ & $\mathrm{D}_{\mathrm{Me}}=1,724 \cdot \mathrm{x}-0,99$ & $\mathrm{D}_{\mathrm{K} 3}=0,566 \cdot \mathrm{x}-0,385$ & $D_{3 e}=0,542 \cdot x^{2}-0,218$ \\
\hline - оптимальное значение & 0,107 & 0,58 & 0,69 & 0,403 \\
\hline \multicolumn{5}{|c|}{ Уход за вступающими и плодоносящими насаждениями } \\
\hline $\begin{array}{l}\text { - дифференцированное } \\
\text { уравнение регрессии }\end{array}$ & $\mathrm{D}_{\mathrm{AM}}=-0,362 \cdot \mathrm{x}+0,399$ & $\mathrm{D}_{\mathrm{Me}}=0,324 \cdot \mathrm{x}-3,233$ & $\mathrm{D}_{\mathrm{K} 3}=0,302 \cdot \mathrm{x}^{2}-0,948$ & $\mathrm{D}_{3 \mathrm{e}}=2.48 \cdot \mathrm{x}-1,664$ \\
\hline - оптимальное значение & 1,103 & 2,641 & 3,139 & 0,671 \\
\hline \multicolumn{5}{|c|}{ Уборка урожая } \\
\hline $\begin{array}{l}\text { - дифференцированное } \\
\text { уравнение регрессии }\end{array}$ & $\mathrm{D}_{\mathrm{AM}}=-0,028 \cdot \mathrm{x}+0,0012$ & $\mathrm{D}_{\mathrm{Me}}=0,248 \cdot \mathrm{x}-0,0087$ & $\mathrm{D}_{\mathrm{K}_{3}}=1,848 \cdot \mathrm{x}-0,078 \cdot$ & $\mathrm{D}_{3 \mathrm{e}}=1,774 \cdot \mathrm{x}-1,038$ \\
\hline - оптимальное значение & 0,042 & 0,035 & 0,042 & 0,585 \\
\hline
\end{tabular}

http://ej.kubagro.ru/2019/07/pdf/21.pdf 
На основании полученных уравнений регрессий было рассчитано нормативное значение совокупного индекса ресурсоемкости по технологическим процессам (рисунок 1).

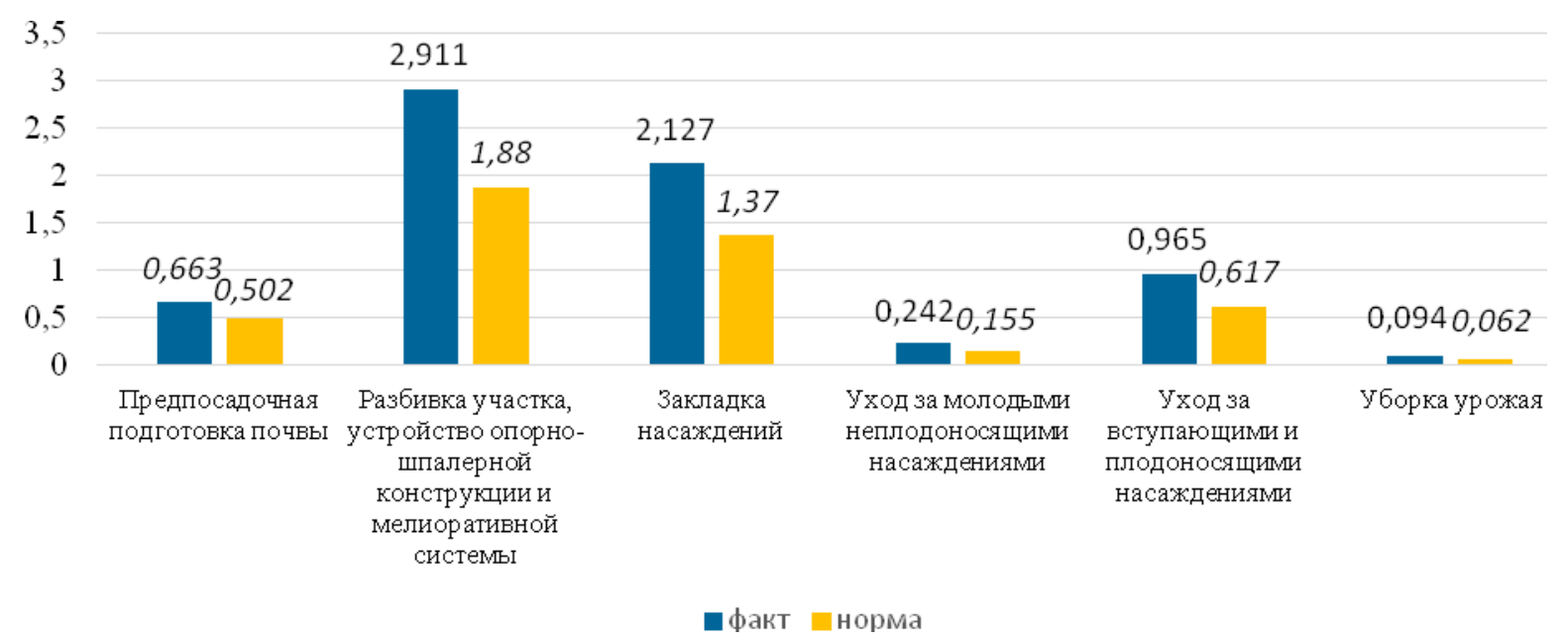

Рисунок 1 - Сопоставимая характеристика фактических и нормативных показателей ресурсоемкости производственно-технологических процессов в промышленном плодоводстве

Заключение. Таким образом, по всем стадиям технологического процесса в промышленном плодоводстве наблюдается несоблюдение нормативных значений показателей ресурсоемкости, что обуславливает необходимость разработки направлений по снижению ресурсоёмкости и повышению эффективности и конкурентоспособности производства отраслевой продукции.

\section{Список литературы}

1. Егоров Е. А. Механизм управления эколого-экономической устойчивостью агроэкосистемы / Е. А. Егоров, Ж. А. Шадрина, Г. А. Кочьян // Экономика и предпринимательство. - 2015. - № 4 (ч. 2). - С. 363-368. - Режим доступа: https://elibrary.ru/item.asp?id=27616835

2. Егоров Е.А. Оптимизация воспроизводственных процессов в промышленном плодоводстве / Е.А. Егоров, Ж.А. Шадрина, Г.А. Кочьян // Экономика сельскохозяйственных и перерабатывающих предприятий. - 2009. - № 10. - С. 40-42.

3. Сороко Э.М. Золотые сечения, процессы самоорганизации и эволюции систем. Введение в общую теорию гармонии систем / Э.М. Сороко. - М.: КомКнига, 2006. -264 c. 
4. Габдулхакова О.И. Экологическая экспертиза проектов и оценка воздействия на окружающую среду/ О.И. Габдулхакова, Э.М. Ахметшин, В.Л. Васильев, Ю.И. Хорошилова // Экономика и менеджмент систем управления. - 2018. - Т. 27. - № 1. - С. $18-25$.

5. Кульметьев Р.И. Способы раскрытия инновационного потенциала организации / Р.И. Кульметьев, Э.М. Ахметшин, В.Л. Васильев // Экономика и предпринимательство. - 2017. - № 10-2 (87). - С. 483-486.

\section{References}

1. Egorov E. A. Mekhanizm upravleniya ekologo-ekonomicheskoj ustojchivost'yu agroekosistemy / E. A. Egorov, ZH. A. SHadrina, G. A. Koch'yan // Ekonomika i predprinimatel'stvo. - 2015. - № 4 (ch. 2). - S. 363-368. - Rezhim dostupa: https://elibrary.ru/item.asp?id=27616835

2. Egorov E.A. Optimizaciya vosproizvodstvennyh processov v promyshlennom plodovodstve / E.A. Egorov, ZH.A. SHadrina, G.A. Koch'yan // Ekonomika sel'skohozyajstvennyh i pererabatyvayushchih predpriyatij. - 2009. - № 10. - S. 40-42.

3. Soroko E.M. Zolotye secheniya, processy samoorganizacii i evolyucii sistem. Vvedenie v obshchuyu teoriyu garmonii sistem / E.M. Soroko. - M.: KomKniga, 2006. - 264 s.

4. Gabdulhakova O.I. Ekologicheskaya ekspertiza proektov i ocenka vozdejstviya na okruzhayushchuyu sredu/ O.I. Gabdulhakova, E.M. Ahmetshin, V.L. Vasil'ev, YU.I. Horoshilova // Ekonomika i menedzhment sistem upravleniya. - 2018. - T. 27. - № 1. - S. $18-25$.

5. Kul'met'ev R.I. Sposoby raskrytiya innovacionnogo potenciala organizacii / R.I. Kul'met'ev, E.M. Ahmetshin, V.L. Vasil'ev // Ekonomika i predprinimatel'stvo. - 2017. - № 10-2 (87). - S. 483-486. 